\title{
Exercise stress assessed by automated measurements of salivary testosterone and cortisol levels and testosterone/cortisol ratio within circadian rhythms in male long-distance runners
}

\section{Larasati Martha}

Gunma University Graduate School of Medicine School of Medicine: Gunma Daigaku Daigakuin Igakukei Kenkyuka Igakubu

Katsuhiko Tsunekawa ( $\nabla$ ktsune@gunma-u.ac.jp)

Gunma University Graduate School of Medicine https://orcid.org/0000-0002-6119-4158

\section{Kazumi Ushiki}

Gunma University Graduate School of Medicine School of Medicine: Gunma Daigaku Daigakuin Igakukei Kenkyuka Igakubu

\section{Yoshifumi Shoho}

Ikuei University: Ikuei Daigaku

\section{Yoshimaro Yanagawa}

Ikuei University: Ikuei Daigaku

\section{Koji Hase}

Ikuei University: Ikuei Daigaku

\section{Nozomi Shimoda}

Gunma University Graduate School of Medicine School of Medicine: Gunma Daigaku Daigakuin Igakukei Kenkyuka Igakubu

\section{Mai Murata}

Gunma University Graduate School of Medicine School of Medicine: Gunma Daigaku Daigakuin Igakukei Kenkyuka Igakubu

\section{Tomoyuki Aoki}

Gunma University Graduate School of Medicine School of Medicine: Gunma Daigaku Daigakuin Igakukei Kenkyuka Igakubu

\section{Akihiro Yoshida}

Gunma University Graduate School of Medicine School of Medicine: Gunma Daigaku Daigakuin Igakukei Kenkyuka Igakubu

\section{Kiyomi Nakajima}

Gunma University Graduate School of Medicine School of Medicine: Gunma Daigaku Daigakuin Igakukei Kenkyuka Igakubu

\section{Takao Kimura}

Gunma University Graduate School of Medicine School of Medicine: Gunma Daigaku Daigakuin Igakukei Kenkyuka Igakubu

\section{Masami Murakami}

Gunma University Graduate School of Medicine School of Medicine: Gunma Daigaku Daigakuin Igakukei Kenkyuka Igakubu 


\section{Research article}

Keywords: sequential saliva sampling, testosterone/cortisol ratio (T/C ratio), passive drooling, electrochemiluminescence immunoassay (ECLIA)

Posted Date: April 21st, 2021

DOI: https://doi.org/10.21203/rs.3.rs-443484/v1

License: (c) (i) This work is licensed under a Creative Commons Attribution 4.0 International License. Read Full License 


\section{Abstract}

Background: Exercise stress promoted cortisol and testosterone secretions that have their own circadian rhythms. It is necessary that the testosterone, cortisol and testosterone/cortisol ratio ( $\mathrm{T} / \mathrm{C}$ ratio) are measured through their rhythms for use in monitoring exercise-induced stress in athletes. Automated measurement has not been applied to salivary testosterone, which requires passive drooling difficult to collect sufficient saliva rapidly. This study aimed to verify whether automated measurements of the testosterone and cortisol concentrations and $\mathrm{T} / \mathrm{C}$ ratio using saliva collected sequentially can effectively assess exercise intensity differences within circadian rhythms in male athletes.

Methods: We investigated the correlations of testosterone and cortisol concentrations measured by electrochemiluminescence immunoassay (ECLIA) between saliva and sera collected from 20 male long-distance runners. We collected the runners' saliva sequentially by passive drooling on two consecutive days involving different intensity trainings in the morning and evening; salivary testosterone and cortisol concentrations were measured by ECLIA. Each exercise intensity was measured by running distances, velocities, Borg scale score and maximum pulse rate during exercise.

Results: The salivary testosterone and cortisol concentrations were positively correlated with the respective total serum hormone concentrations. The runners were divided into low-intensity exercise group $(n=8)$ and high-intensity exercise group $(n=7)$, in which five runners were excluded because measurable saliva samples could not be obtained due to low volume and high-viscosity. Sequential saliva collection and automated measurements detected the runners' circadian rhythms of testosterone, cortisol and $\mathrm{T} / \mathrm{C}$ ratio. The rate of change in the salivary cortisol concentrations were significantly higher and that in the $\mathrm{T} / \mathrm{C}$ ratio was significantly lower in the evening interval training on day 1 in the highintensity exercise group which had significantly higher running velocity, Borg scale score, and maximum pulse rate values; this relationship was not shown for salivary testosterone.

Conclusions: Automated measurements of the salivary cortisol concentration and the T/C ratio reflected different exercise intensities may be useful for creating appropriate exercise programs for athletes. Conversely, the automated measurements of salivary testosterone and $\mathrm{T} / \mathrm{C}$ ratio, which require passive drooling to collect saliva, may be less suitable for practical use with athletes than the salivary cortisol-only measurement

\section{Background}

Cortisol and testosterone secretions are promoted by physical and psychological stress, including resistance and endurance exercise, from the adrenal cortex and testes, respectively, via the hypothalamic pituitary axis in men [1]. These hormones have their own circadian rhythms: circulating cortisol levels peak at 30 min after awakening and then promptly decrease toward evening whereas circulating testosterone levels peak at the time of awakening and gradually decrease thereafter toward evening [1]. Excessive overloading of athletes during training increases physical and psychological stress, resulting in reduced performance, which is called overtraining syndrome [2]. Overtraining syndrome presents with a reduced cortisol response to exercise and changes in circadian rhythms such as low levels of resting cortisol and peak loss after awakening [2, 3]. Overtraining syndrome also reportedly reduces the resting testosterone level in athletes [3]. Monitoring of these hormone secretions throughout their circadian rhythms is expected to lead to the development of appropriate training programs for athletes to assess and prevent overtraining syndrome due to excessive stress. Moreover, the testosterone cortisol ratio ( $\mathrm{T} / \mathrm{C}$ ratio) calculated by testosterone and cortisol levels is reduced by exercise-induced stress [4]. Because the testosterone and cortisol levels have their own circadian rhythms, it is necessary that the testosterone, cortisol and $\mathrm{T} / \mathrm{C}$ ratio are assessed through their own circadian rhythms for use in monitoring exercise-induced stress in athletes. 
Cortisol and testosterone levels are commonly measured by immunological methods using serum and saliva specimens. Saliva sampling has several advantages; for example, it is a stress-free and non-invasive simple method that does not require medical professional staff, which is necessary for blood sampling [5]. Moreover, although cortisol and testosterone are mostly conjugated to corticosteroid-binding globulin and sex hormone-binding globulin, respectively, in serum, both steroid hormones are unconjugated in saliva. Therefore, salivary concentrations of cortisol and testosterone are more positively correlated with the serum concentrations of free cortisol and free testosterone than the serum concentrations of total cortisol and total testosterone, respectively [6, 7]. It is important to monitor stress induced by exercise of different intensity by measuring these hormones within circadian rhythms, which may help prevent overtraining syndrome. This monitoring requires sequential sampling within circadian rhythms throughout days with different exercise training intensities and the efficient measurement of a large number of such samples. We previously reported that sequential saliva sampling and automated electrochemiluminescence immunoassay (ECLIA)-based salivary cortisol measurements made it possible to detect the circadian rhythm and to compare the stress induced by different intensities of endurance exercise at the same time on different days in female long-distance runners [8]. By contrast, there have been no reports of similar saliva sampling and automated measurements of testosterone for assessing exercise stress in male athletes.

Commonly used methods for saliva sampling include cotton swabbing and passive drooling. The cotton swab is a convenient method to quickly collect a sufficient amount of saliva without residues and mucus for measuring stress markers [9]; additionally, the cortisol in cotton swab samples was a better predictor of the serum concentrations of total cortisol and free cortisol than passive drooling [6]. In contrast, because saliva collected with a cotton swab has falsely higher testosterone levels, passive drooling, which requires a significant amount of time to collect saliva including residues and mucus, is a suitable collection method for measuring testosterone levels in saliva [10]. It is hypothesized that the automated measurement of salivary testosterone concentrations or the $\mathrm{T} / \mathrm{C}$ ratio is effective in assessing exercise-induced stress within circadian rhythms in male athletes, even using passive drooling. If the combination of salivary testosterone and cortisol measurements can adequately assess the changes in stress due to different exercise intensities within the circadian rhythms, this method may be useful for providing exercise programs to improve the performance of athletes. However, if the salivary cortisol-only measurement more appropriately reflects the different exercise intensities, a simple and quick sampling method using a cotton swab would be more practical than the passive drooling method. In the present study, we expanded upon our previous study to test the hypothesis by comparing changes in the concentrations of testosterone and cortisol and the $\mathrm{T} / \mathrm{C}$ ratio, using saliva collected by the passive drooling method and measured with an automated ECLIA, between different exercise intensities within the circadian rhythms in male long-distance runners.

\section{Methods}

\section{Participants}

This investigation prospective study was conducted according to the Declaration of Helsinki and the protocol was approved by the ethics committee of the Gunma University Graduate School of Medicine (Approval number HS2018-030, HS2018-140). All the participants study subjects provided written informed consent before being included prior to participation in the study.

We enrolled 20 Japanese elite male runners. All runners lived in the same dormitory and Their their conditions of lifestyles, such as wakeup time, meal time, bedtime, and meal content, were standardized living in the same dormitory. We collected saliva and serum samples for correlation analyses of the testosterone and cortisol concentrations from all runners at 7:00 before morning exercise and breakfast. Four weeks later, we collected salivary samples were collected sequentially from these runners on two consecutive days involving different intensities and types of training in the

Page $4 / 16$ 
morning and evening during a training period sufficiently removed from races, as previously described [8]. We divided the runners into two groups; a low-intensity exercise group and a high-intensity exercise group. The runners in the lowintensity exercise group were subjected to the following exercise program: day 1, walking and light jogging for 60 min in the morning and light jogging for $60 \mathrm{~min}$ in the evening; day 2, fixed-distance running from 6,000 to 12,000 -m for each runner in the morning and walking and light jogging for $60 \mathrm{~min}$ in the evening. The runners in the high-intensity exercise group were subjected to the following exercise program: day 1, 12,000-m fixed-distance speed running in the morning and interval training with seven sets of 1,000-m fast running and light jogging in the evening; day 2, 10,000-m fixeddistance running in the morning and 15,000-m fixed-distance running in the evening. The runners were allowed to drink drank enough water to avoid dehydration during these training sessions [8]. On both days, saliva samples were collected at eight time points: upon waking (05:00), before morning exercise (05:30), after morning exercise (07:00), before breakfast (07:30), before lunch (12:00), before evening exercise (16:00), after evening exercise (18:30), and before dinner (19:00), as previously described [8].

\section{Physical examinations and measurements of exercise intensities}

The participants' weight and body fat were measured using a bioimpedance instrument (InBody 770; InBody Japan, Tokyo, Japan), and the body mass index was calculated as weight divided by height squared $\left(\mathrm{kg} / \mathrm{m}^{2}\right)$. The interviews were performed to obtain the information Information about the use of medications and supplements was obtained through interviews. The runners were instrumented the Fitbit ionic (Fitbit Inc. Tokyo, Japan) on their wrists as wearable devices beginning the day before the two consecutive days of saliva collection. The resting pulse rates at wakeup time and the maximum pulse rates during each exercise session were measured using the wearable devices. The distance and duration of running during each exercise session were was measured, and the running velocity was calculated as the distance divided by the duration ( $\mathrm{m} / \mathrm{min}$ ), as previously described [8]. The Borg Scale [11] was used to determine the rating of perceived exertion of the runners after exercise.

\section{Sample collections}

The saliva samples were collected by unstimulated passive drooling using a polypropylene tube, SaliCap (IBL International, Hamburg, Germany). The runners were not allowed to brush their teeth, chew gum, or consume any food or drink except water within $15 \mathrm{~min}$ before sample collection. All saliva samples were immediately stored at $-80^{\circ} \mathrm{C}$ until analysis. With the participants in the seated position, blood Blood samples were obtained by puncturing an antecubital vein using a $23-\mathrm{G}$ needle while the subject was in a seated position. The serum samples were separated from the blood by centrifugation $(1,500 \times \mathrm{g})$ at $4^{\circ} \mathrm{C}$ for $10 \mathrm{~min}$ and stored at $-80^{\circ} \mathrm{C}$ until analysis [8].

\section{Measurements of salivary and serum testosterone and cortisol concentrations}

The ECLIA measurements of salivary and serum testosterone and cortisol concentrations were performed using the Elecsys Testosterone II and Elecsys Cortisol $\mathbb{Z}$ on the Cobas 8000 system (Roche Diagnostics K.K, Tokyo, Japan). The intra- and inter-assay coefficients of variation were $4.2 \%$ and $5.6 \%$ for salivary testosterone, $1.7 \%$ and $1.6 \%$ for serum testosterone, $4.1 \%$ and $4.6 \%$ for salivary cortisol, and $1.3 \%$ and $3.4 \%$ for serum cortisol, respectively. The salivary and the serum $\mathrm{T} / \mathrm{C}$ ratios were calculated as the salivary testosterone concentration divided by the salivary cortisol concentration and the serum testosterone concentration divided by the serum cortisol concentration, respectively. The rate of change in the salivary concentrations of testosterone and cortisol and the salivary $\mathrm{T} / \mathrm{C}$ ratio due to exercise were calculated as each concentration and ratio after exercise divided by each concentration and ratio before exercise (\%).

\section{Statistical analysis}

The results of each measurement are expressed as the median values and the corresponding 25th - 75th percentile ranges. Spearman's correlation analyses were used to assess the correlations between the salivary and serum values of testosterone, cortisol, and the T/C ratio. The Mann-Whitney Utest was used to identify statistically significant differences of each variable between the high-intensity and low-intensity exercise groups. The Wilcoxon signed-rank test 
was used to identify statistically significant differences of each variable between two different time points. A Differences and correlations were considered significant when $p$ value of $<0.05$ was considered to indicate a significant difference. All statistical analyses were performed using SPSS Statistics, version 25.0 (IBM Corp., Armonk, NY, SPSS, Chicago, IL, USA).

\section{Results}

\section{Correlations between salivary and serum concentrations of testosterone, cortisol, and the T/C ratio determined by ECLIA}

Table 1 shows the characteristics of the 20 long-distance runners. The results of Spearman's correlation analyses between the concentrations of salivary testosterone and serum testosterone, between the concentrations of salivary cortisol and serum cortisol, and between the salivary $\mathrm{T} / \mathrm{C}$ ratio and the serum $\mathrm{T} / \mathrm{C}$ ratio determined by ECLIA are shown in Fig. 1. The salivary testosterone concentrations and the serum testosterone concentrations exhibited a significant positive correlation $(\rho=0.702, p<0.001)$. Moreover, the salivary cortisol concentrations were positively correlated with the serum cortisol concentrations $(\rho=0.586, p=0.007)$. There was a significant positive correlation between the salivary $\mathrm{T} / \mathrm{C}$ ratio and the serum $\mathrm{T} / \mathrm{C}$ ratio calculated by each sample $(\rho=0.618, p=0.004)$.

Table 1

Characteristics of all male long-distance runners.

\begin{tabular}{|ll|}
\hline Characteristics & Value \\
\hline Number & 20 \\
\hline Age (years) & $19.0(19.0-19.0)$ \\
\hline Height $(\mathrm{cm})$ & $170.5(166.5-173.0)$ \\
\hline Weight $(\mathrm{kg})$ & $57.1(54.6-60.8)$ \\
\hline Body mass index $\left(\mathrm{kg} / \mathrm{m}^{2}\right)$ & $19.5(19.1-20.0)$ \\
\hline Body fat $(\%)$ & $11.4(9.3-13.3)$ \\
\hline Data are expressed as the median (25th-75th percentile). \\
\hline
\end{tabular}

\section{Running intensity of each exercise program performed by male long-distance runners}

Group division of the runners is shown in Fig. 2. Twelve runners who practiced high-intensity exercise were included in the high-intensity exercise group, and eight runners who were not in sufficient condition to perform high-intensity training were included in the low-intensity exercise group. In the high-intensity exercise group, five runners were excluded because measurable saliva samples could not be obtained due to low volume $(n=2)$ and high-viscosity $(n=3)$. Finally, seven runners were in the high-intensity exercise group. Table 2 shows the characteristics among each group of runners. There were no significant differences in body height, weight, body mass index, body fat, and resting pulse rate on days 1 and 2 between the two groups. Table 3 presents the differences of the running intensities in the runners of the two groups during each exercise program. The running velocity, Borg scale score and maximum pulse rate during the evening exercise on day 1 were significantly higher in the high-intensity exercise group than in the low-intensity exercise group (running velocity, $p=0.014$; Borg scale score, $p<0.001$; maximum pulse rate, $p=0.001$ ). Additionally, the running velocity, Borg scale score, and maximum pulse rate during the evening exercise were significantly higher on day 1 than on day 2 in the high-intensity exercise group (running velocity, $p=0.043$; Borg scale score, $p=0.018$; maximum pulse rate, $p=$ 0.018). The Borg scale score on day 1 was also significantly higher during the evening exercise than the morning 
exercise in the high-intensity exercise group $(p=0.017)$. The running velocities during the morning exercise on day 1 in the high-intensity exercise was significantly higher than the low-intensity exercise group $(p=0.043)$ and was significantly higher than on day 2 in same group $(p=0.046)$. The running distance during the evening exercise on day 2 in the highintensity exercise was significantly longer than the low-intensity exercise group $(p=0.009)$ and was significantly longer than in the morning exercise on day 2 in same group $(p=0.028)$. The running distance was significantly longer in the evening exercise than in the morning exercise in the low-intensity exercise group on day $1(p=0.043)$. The running velocity and Borg scale scores during the morning exercise were significantly higher on day 2 than on day 1 in the lowintensity exercise group (running velocity, $p=0.043$; Borg scale score, $p=0.041$ ).

Table 2

Characteristics among each group of runners divided by their exercise intensities.

\begin{tabular}{|llll|}
\hline & Low-intensity exercise group & High-intensity exercise group & $p$ \\
\hline Number & 8 & 7 & 0.694 \\
\hline Age (years) & $19.0(18.5-20.5)$ & $19.0(19.0-19.0)$ & 0.536 \\
\hline Height $(\mathrm{cm})$ & $169.5(168.0-171.0)$ & $166.0(165.5-172.5)$ & 0.536 \\
\hline Weight $(\mathrm{kg})$ & $55.2(53.7-57.2)$ & $57.5(53.9-59.8)$ & 0.232 \\
\hline Body mass index $\left(\mathrm{kg} / \mathrm{m}^{2}\right)$ & $19.1(18.8-19.9)$ & $19.6(19.4-20.1)$ & 0.779 \\
\hline Body fat $(\%)$ & $11.2(7.3-13.8)$ & $11.6(10.4-12.9)$ & 0.121 \\
\hline Resting pulse rate on day 1 (beat/min) & $55(53-59)$ & $48(43-50.5)$ & 0.072 \\
\hline Resting pulse rate on day 2 (beat/min) & $59(53-60)$ & $47(42-49)$ & \\
\hline Data are expressed as the median $(25 t h-75 t h$ percentile). & & \\
\hline The groups divided by exercise intensities were compared using the Mann-Whitney Utest. & \\
\hline
\end{tabular}


Table 3

Running intensities during each exercise program performed by long-distance runners.

\begin{tabular}{|c|c|c|c|c|c|c|c|c|c|}
\hline & \multirow{2}{*}{$\begin{array}{l}\text { Intensity } \\
\text { exercise } \\
\text { group }\end{array}$} & \multicolumn{3}{|l|}{ Day 1} & \multicolumn{3}{|l|}{ Day 2} & \multicolumn{2}{|c|}{$\begin{array}{l}\text { Day } 1 \text { vs. Day } \\
2\end{array}$} \\
\hline & & $\begin{array}{l}\text { morning } \\
\text { exercise }\end{array}$ & $\begin{array}{l}\text { evening } \\
\text { exercise }\end{array}$ & $p_{\text {day } 1}$ & $\begin{array}{l}\text { morning } \\
\text { exercise }\end{array}$ & $\begin{array}{l}\text { evening } \\
\text { exercise }\end{array}$ & $p_{\text {day2 }}$ & $p_{m}$ & $p_{e}$ \\
\hline \multirow[t]{2}{*}{$\begin{array}{l}\text { Exercise } \\
\text { program }\end{array}$} & $\begin{array}{l}\text { Low }(\mathrm{n} \\
=8)\end{array}$ & $\begin{array}{l}\text { walking } \\
\text { and } \\
\text { jogging }\end{array}$ & jogging & & $\begin{array}{l}\text { fixed- } \\
\text { distance } \\
\text { running }\end{array}$ & $\begin{array}{l}\text { walking } \\
\text { and } \\
\text { jogging }\end{array}$ & & & \\
\hline & $\begin{array}{l}\text { High (n } \\
=7)\end{array}$ & $\begin{array}{l}\text { fixed- } \\
\text { distance } \\
\text { running }\end{array}$ & $\begin{array}{l}\text { interval } \\
\text { training }\end{array}$ & & $\begin{array}{l}\text { fixed- } \\
\text { distance } \\
\text { running }\end{array}$ & $\begin{array}{l}\text { fixed- } \\
\text { distance } \\
\text { running }\end{array}$ & & & \\
\hline $\begin{array}{l}\text { Running } \\
\text { distance }\end{array}$ & $\begin{array}{l}\text { Low }(\mathrm{n} \\
=8)\end{array}$ & $\begin{array}{l}7,751 \\
(6,527- \\
10,490)\end{array}$ & $\begin{array}{l}9,420 \\
(7,225- \\
11,500)\end{array}$ & 0.043 & $\begin{array}{l}11,000 \\
(6,850- \\
12,000)\end{array}$ & $\begin{array}{l}9,215 \\
(8,000- \\
13,500)\end{array}$ & 0.496 & 0.075 & 0.441 \\
\hline (m) & $\begin{array}{l}\text { High }(\mathrm{n} \\
=7)\end{array}$ & $\begin{array}{l}12,000 \\
(10,935- \\
12,000)\end{array}$ & $\begin{array}{l}10,000 \\
(9,100- \\
12,500)\end{array}$ & 0.866 & $\begin{array}{l}10,270 \\
(10,000- \\
11,300)\end{array}$ & $\begin{array}{l}15,070 \\
(15,000- \\
15,605)^{\star \star}\end{array}$ & 0.028 & 0.141 & 0.116 \\
\hline $\begin{array}{l}\text { Running } \\
\text { velocity }\end{array}$ & $\begin{array}{l}\text { Low }(\mathrm{n} \\
=8)\end{array}$ & $\begin{array}{l}139.4 \\
(127.5- \\
167.3)\end{array}$ & $\begin{array}{l}157.0 \\
(141.7- \\
177.4)\end{array}$ & 0.116 & $\begin{array}{l}200.0 \\
(136.7- \\
217.5)\end{array}$ & $\begin{array}{l}157.8 \\
(111.6- \\
177.8)\end{array}$ & 0.123 & 0.043 & 1.000 \\
\hline$(\mathrm{m} / \mathrm{min})$ & $\begin{array}{l}\text { High (n } \\
=7 \text { ) }\end{array}$ & $\begin{array}{l}200.0 \\
(179.2- \\
236.8)^{\star}\end{array}$ & $\begin{array}{l}268.8 \\
(211.8- \\
314.8)^{\star}\end{array}$ & 0.176 & $\begin{array}{l}166.7 \\
(163.6- \\
188.4)\end{array}$ & $\begin{array}{l}180.7 \\
(175.7- \\
207.2)\end{array}$ & 0.398 & 0.046 & 0.043 \\
\hline \multirow[t]{2}{*}{$\begin{array}{l}\text { Borg Scale } \\
\text { score }\end{array}$} & $\begin{array}{l}\text { Low (n } \\
=8)\end{array}$ & $\begin{array}{l}10.0 \\
(8.0- \\
13.0)\end{array}$ & $\begin{array}{l}11.0 \\
(8.5- \\
11.0)\end{array}$ & 0.932 & $\begin{array}{l}12.5 \\
(11.5- \\
14.0)\end{array}$ & $\begin{array}{l}11.0 \\
(9.5- \\
11.5)\end{array}$ & 0.175 & 0.041 & 0.893 \\
\hline & $\begin{array}{l}\text { High }(\mathrm{n} \\
=7)\end{array}$ & $\begin{array}{l}12.0 \\
(11.0- \\
13.0)\end{array}$ & $\begin{array}{l}16.0 \\
(15.5- \\
17.5)^{\star \star}\end{array}$ & 0.017 & $\begin{array}{l}11.0 \\
(9.5- \\
11.5)\end{array}$ & $\begin{array}{l}12.0 \\
(9.5- \\
13.5)\end{array}$ & 0.078 & 0.063 & 0.018 \\
\hline $\begin{array}{l}\text { Maximum } \\
\text { pulse }\end{array}$ & $\begin{array}{l}\text { Low }(\mathrm{n} \\
=8)\end{array}$ & $\begin{array}{l}169 \\
(151- \\
175)\end{array}$ & $\begin{array}{l}160 \\
(138- \\
173)\end{array}$ & 0.262 & $\begin{array}{l}172 \\
(163- \\
183)\end{array}$ & $\begin{array}{l}136 \\
(120- \\
170)\end{array}$ & 0.068 & 0.176 & 0.225 \\
\hline $\begin{array}{l}\text { rate } \\
\text { (beat/min) }\end{array}$ & $\begin{array}{l}\text { High (n } \\
=7 \text { ) }\end{array}$ & $\begin{array}{l}181 \\
(177- \\
187)\end{array}$ & $\begin{array}{l}196 \\
(194- \\
200)^{\star \star}\end{array}$ & 0.063 & $\begin{array}{l}173 \\
(137- \\
175)\end{array}$ & $\begin{array}{l}144 \\
(142- \\
179)\end{array}$ & 0.612 & 0.046 & 0.018 \\
\hline \multicolumn{10}{|c|}{ Data are expressed as the median (25th-75th percentile). } \\
\hline \multicolumn{10}{|c|}{$\begin{array}{l}* p<0.05 \text { and } * * p<0.01 \text { comparing variables between the two groups divided by their exercise intensities using the } \\
\text { Mann-Whitney U test. }\end{array}$} \\
\hline \multicolumn{10}{|c|}{$p_{\text {day } 1}$ morning exercise vs. evening exercise on day 1 using the Wilcoxon signed-rank test. } \\
\hline \multicolumn{10}{|c|}{$p_{\text {day } 2}$ morning exercise vs. evening exercise on day 2 using the Wilcoxon signed-rank test. } \\
\hline \multicolumn{10}{|c|}{$p_{\mathrm{m}}$ day 1 vs. day 2 for morning exercise using the Wilcoxon signed-rank test. } \\
\hline$p_{\mathrm{e}}$ day $1 \mathrm{vs}$ & 2 for & ng exero & (i) & & d-rank & & & & \\
\hline
\end{tabular}




\section{Changes in the concentrations of salivary testosterone and cortisol, and the T/C ratio in response to exercise during circadian rhythms on two consecutive days in the two exercise intensity groups}

Figure 3 demonstrates changes in the concentrations of salivary testosterone and cortisol and the T/C ratio in response to exercise within the circadian rhythms of the two groups of runners during two consecutive days. Although several runners in each group had low salivary concentrations of cortisol at awakening, there was no significant difference in the concentrations of cortisol and testosterone and the $\mathrm{T} / \mathrm{C}$ ratio on each day between the two groups (data not shown). The salivary testosterone concentrations gradually decreased from morning to evening, and the salivary cortisol concentrations peaked after waking (05:30) and immediately decreased on both days in the two groups. Furthermore, the $\mathrm{T} / \mathrm{C}$ ratio bottomed out $30 \mathrm{~min}$ after awakening and then gradually increased, as the results, the circadian rhythms of salivary testosterone, cortisol and $\mathrm{T} / \mathrm{C}$ ratio were detected on both days in the two groups. Although there were no significant changes in the salivary testosterone and cortisol concentrations and the T/C ratio after morning exercise, the salivary testosterone concentrations significantly increased after the evening exercise on both days in both groups. There were no significant changes in the salivary cortisol concentrations and the $\mathrm{T} / \mathrm{C}$ ratio after evening exercise on both days in the low-intensity exercise group. However, the salivary cortisol concentrations after evening exercise significantly increased on day 1 and significantly decreased on day 2 in the high-intensity exercise group. Moreover, the T/C ratio after evening exercise significantly decreased on day 1 and significantly increased on day 2 in the high-intensity exercise group.

\section{Rate of change in the concentrations of salivary testosterone and cortisol, and the $T / C$ ratio resulting from exercise in runners}

Figure 4 shows comparisons in the rates of change in the salivary concentrations of testosterone and cortisol, and the $\mathrm{T} / \mathrm{C}$ ratio resulting from exercise between two different time points in two groups. The rate of change in the salivary cortisol concentration was significantly higher and the rate of change in the T/C ratio was significantly lower in the highintensity exercise group than in the low-intensity exercise group during the evening exercise on day 1 (cortisol, $p=0.014$; $\mathrm{T} / \mathrm{C}$ ratio, $p=0.006$ ). Moreover, during the evening exercise in the high-intensity exercise group, the rate of change in the salivary cortisol concentration was significantly higher and the rate of change in the T/C ratio was significantly lower on day 1 than on day 2 (cortisol, $p=0.018 ; T / C$ ratio, $p=0.018$ ). The rate of change in the $T / C$ ratio was also significantly lower in the evening than in the morning on day 1 in the high-intensity exercise group $(p=0.028)$. On day 2 , the rates of change in the salivary testosterone concentration and the $\mathrm{T} / \mathrm{C}$ ratio were significantly higher and the rate of change in the salivary cortisol concentration was significantly lower during the evening exercise than during the morning exercise in the high-intensity exercise group (testosterone, $p=0.018$; cortisol, $p=0.028 ; \mathrm{T} / \mathrm{C}$ ratio, $p=0.028$ ).

\section{Discussion}

In this study, we have demonstrated that salivary testosterone and cortisol concentrations and the salivary $\mathrm{T} / \mathrm{C}$ ratio evaluated by automated ECLIA measurements can appropriately assess the stress induced by different intensities of exercise within the circadian rhythm in male long-distance runners. The combination of sequential saliva collection by passive drooling and automated ECLIA measurements made it possible to detect the circadian rhythms of testosterone and cortisol levels and T/C ratio and to identify the acute changes in these hormone levels due to exercise within each rhythm, although the measurable saliva samples could not be obtained due to low volume and high viscosities in five runners. The interval training in the evening on day 1 in the high-intensity exercise group had a significant higher running velocity and significantly increased the runners' Borg scale score and maximum pulse rate. The rate of change in salivary cortisol concentrations was significantly higher and that in the $\mathrm{T} / \mathrm{C}$ ratio was significantly lower during the interval training on day 1 in the high-intensity exercise group; these changes were not observed for the salivary testosterone concentrations. 
Salivary cortisol concentrations measured by automated second-generation ECLIA were significantly positively correlated with those measured by liquid chromatography-tandem mass spectrometry (LC-MS/MS) [12]. We previously assessed the exercise-induced stress by combining this automated measurement of salivary cortisol concentration with sequential sampling with a cotton swab in female long-distance runners [8]. In this study, the salivary cortisol concentration measured by ECLIA was significantly positively correlated with those measured by enzyme-linked immunosorbent assay, and all salivary samples could be measured without low-dose or high-viscosity samples collected by cotton swabs. The present study is the first report to measure the salivary testosterone concentration by applying automated second-generation ECLIA for serum samples. The salivary testosterone concentration measured by ECLIA was significantly positively correlated with the serum total testosterone concentration and could be used to assess the runners' circadian rhythm combined with sequential sampling using passive drooling. However, serum-free testosterone concentrations were not analyzed for correlation with the salivary testosterone concentration. Moreover, there were several runners whose collected saliva by passive drooling was not sufficient and was too viscous to measure by ECLIA. Physical and mental stress reduce the flow rate and increase the viscosity of saliva $[13,14]$. In contrast, assays including ECLIA require a sufficient sample volume (minimum of $100-200 \mathrm{~mL}$ ) because of the dead volume required for troublefree automated sample processing. Although the automated ECLIA methods for measuring the salivary concentrations of cortisol and testosterone have the advantages of being able to measure a large number of samples easily and rapidly, its usefulness may be reduced in combination with passive drooling, which is a difficult method for collecting a large sample volume without residues and mucus.

Previous studies have noted that serum cortisol concentrations were acutely elevated by moderate- to high-intensity endurance exercise (more than $60 \%$ of the maximal oxygen consumption $\left(\mathrm{VO}_{2}\right.$ max $)$ ) $[15,16]$. Resistance exercise acutely increases testosterone secretion, which is an anabolic hormone essential for muscular adaptation and muscle growth [1]. In contrast, there are conflicting reports of the acute response of testosterone during endurance exercise. In healthy young men, serum cortisol and free testosterone concentrations were elevated by acute exercise at $40 \%$ or higher of the peak oxygen uptake $\left(\mathrm{VO}_{2}\right.$ peak $)$ in non-athletes, but only by exercise at $90 \%$ of the $\mathrm{VO}_{2}$ peak in endurance runners [17]. Longer duration runs of at least 80 min are necessary to increase testosterone and cortisol levels during low-intensity endurance exercise [18]. However, a previous meta-analysis demonstrated that the acute responses of salivary testosterone to exercise are weak [4]. Moreover, serum-free testosterone concentration decreases immediately after exhaustive endurance exercise and gradually increases after 24 hours or later on during the recovery process in male endurance athletes [19]. In the present study, the interval training during the evening on day 1 in the high-intensity exercise group, which was the highest intensity exercise based on the indicators including running velocity, Borg scale score, and maximum pulse rate, significantly increased the salivary cortisol concentration and decreased the salivary $\mathrm{T} / \mathrm{C}$ ratio. In contrast, there were no significant differences in the rate of change in the salivary testosterone concentration resulting from each exercise compared between the two groups or between the different exercises within the same group. Moreover, salivary testosterone concentrations were increased after evening exercise on both days in both groups, which suggests that elevated salivary testosterone concentrations do not reflect exercise intensities. Similar results within circadian rhythms were observed during a 36-hole golf competition in which salivary testosterone was elevated only during 25-30 holes in the evening on the competition day compared with baseline day, whereas salivary cortisol was elevated and the salivary $\mathrm{T} / \mathrm{C}$ ratio was lowered at almost every hole on the competition day [20]. In this study, the low $\mathrm{T} / \mathrm{C}$ ratio was also related to good golf performance. The $\mathrm{T} / \mathrm{C}$ ratio is generally considered as an indicator of the anabolic/catabolic balance in the process of skeletal muscle destruction and recovery [21]. In the present study, although the decreased salivary $\mathrm{T} / \mathrm{C}$ ratio reflected the acute stress response during different exercise intensities, we did not assess the differences in the runners' performance or changes in these hormones during recovery. Further study on salivary testosterone concentrations and the $\mathrm{T} / \mathrm{C}$ ratio must investigate the association with the performance or recovery process of endurance- and resistance-trained athletes.

Page 10/16 
It is difficult to detect testosterone and cortisol responses to exercise in the morning due to the influence of their respective rhythms; such measurements can be more easily obtained in the evening [22]. We previously reported that the difference in the rate of change in salivary cortisol concentrations resulting from different exercise intensities could be compared at the same time on different days, even in the early morning [8]. In the present study, there were significant differences in the exercise intensities including running velocities and maximum pulse rates, but there were no differences in the rate of change in salivary concentrations of testosterone and cortisol and the $\mathrm{T} / \mathrm{C}$ ratio resulting from morning exercise between the two days in each exercise intensity group. In contrast, the differences in the rate of change in the cortisol concentration and the $\mathrm{T} / \mathrm{C}$ ratio by evening exercise were observed between the two days, reflecting the exercise intensities. The circadian rhythm of the $\mathrm{T} / \mathrm{C}$ ratio bottomed out $30 \mathrm{~min}$ after awakening and then gradually increased, which is thought to reflect the cortisol rhythm rather than the testosterone rhythm. The rate of change in the salivary $\mathrm{T} / \mathrm{C}$ ratio clearly detected the difference in the stress response between each exercise program. However, the $\mathrm{T} / \mathrm{C}$ ratios, which decreased on day 1 and increased on day 2 after evening exercise, appeared to be more influenced by the response of cortisol than testosterone. A meta-analysis demonstrated the similar results showing that the response of the salivary $\mathrm{T} / \mathrm{C}$ ratio to exercise was largely achieved by changes in salivary cortisol [4]. Because the passive drooling necessary for measuring the $\mathrm{T} / \mathrm{C}$ ratio may not result in an appropriate saliva sample, further study is necessary to verify whether cortisol alone, which can be measured using the saliva conventionally collected by cotton swabs, is sufficient to assess the exercise-induced stress response.

This study has several limitations. Firstly, the sample size in each exercise intensity group was relatively small. We focused on enrolling well-trained male runners living in a standardized environment. However, the number of runners in the high-intensity exercise group was decreased because saliva samples effective for automated measurements could not be obtained by passive drooling which limited this measurement. Secondly, the exercise programs were not fully standardized in the low-intensity exercise group, particularly in the morning on day 2 , and were not evaluated using accurate intensity indicators such as $\mathrm{VO}_{2} \mathrm{max}$. It is necessary to verify the hypothesis with a standardized exercise program for more runners not only in the high-intensity exercise group but also in the low-intensity exercise group using more accurate indicators in further studies. Thirdly, the saliva sampling time was not sufficiently separated between the post-evening exercise point and the pre-dinner point. For this reason, some runners had high salivary hormone levels at the pre-dinner point, which should be the time at which the lowest levels are recorded, particularly for cortisol. Further studies should adjust the collection time according to the training program, such as including a point before bedtime to assess basal levels at night.

\section{Conclusions}

The salivary cortisol concentration and T/C ratio measured by automated ECLIA adequately reflected the differences in endurance exercise intensities within the circadian rhythm, suggesting that these may be useful measurements for providing the appropriate exercise programs for athletes. However, considering the convenience of the saliva collection method, the automated measurement of salivary testosterone and $\mathrm{T} / \mathrm{C}$ ratio, which must be collected by passive drooling, may be less suitable for practical use with athletes than the salivary cortisol-only measurement using cotton swabs.

\section{List Of Abbreviations}

ECLIA: electrochemiluminescence immunoassay, LC-MS/MS: liquid chromatography-tandem mass spectrometry, T/C ratio: testosterone/cortisol ratio, $\mathrm{VO}_{2}$ max: maximal oxygen consumption, $\mathrm{VO}_{2}$ peak: peak oxygen uptake

\section{Declarations}

Page $11 / 16$ 


\section{Ethics approval and consent to participate}

Written informed consent was obtained from all participants. This study was approved by the ethics committee of Gunma University Graduate School of Medicine (Approval number HS2018-030, HS2018-140).

\section{Consent for publication}

Not applicable.

\section{Availability of data and material}

The datasets used and/or analyzed during the current study are available from the corresponding author on reasonable request.

\section{Competing interests}

The authors declare that they have no competing interests.

\section{Funding}

This work was supported by the Ministry of Education, Culture, Sports, Science, and Technology of Japan [grant numbers $18 \mathrm{~K} 07406$ (K. Tsunekawa)]. The funders had no role in the design of the study, the collection, analysis, and interpretations of data, or in writing the manuscript.

\section{Authors' contributions}

LM participated in the collection and analysis of data and writing of the manuscript. KT participated in the conception of the study, analysis of data and manuscript reviewing and editing. KU, YS, YY, NS, MM, TA, AY, NK, and TK participated in data collection and analysis. MM participated in study conception, supervision, and manuscript editing. All authors read and approved the final manuscript.

\section{Acknowledgments}

We are grateful to Hidekazu Shimazu and Mayumi Nishiyama for providing technical assistance and helpful discussion.

\section{Authors' information}

Not applicable

\section{References}

[1] Kraemer WJ, Ratamess NA. Hormonal responses and adaptations to resistance exercise and training. Sports Medicine 2005;35(4):339-361.

[2] Urhausen A, Kindermann W. Diagnosis of overtraining-What tools do we have? Sports Medicine 2002;32(2):95-102.

[3] Cadegiani FA, Kater CE. Novel causes and consequences of overtraining syndrome: the EROS-DISRUPTORS study. BMC Sports Sci Med and Rehabil 2019;11(1):21.

[4] Hayes LD, Grace FM, Baker JS, Sculthorpe N. Exercise-induced responses in salivary testosterone, cortisol, and their ratios in men: A meta-analysis. Sports Medicine. 2015(5);45:713-26. 
[5] Hofman LF. Human saliva as a diagnostic specimen. J Nutr 2001;131(5):1621S-1625S.

[6] Poll E-M, Kreitschmann-Andermahr I, Langejuergen Y, Stanzel S, Gilsbach JM, Gressner A, et al. Saliva collection method affects predictability of serum cortisol. Clin Chim Acta 2007;382(1-2):15-19.

[7] Lippi G, Dipalo M, Buonocore R, Gnocchi C, Aloe R, Delsignore R. Analytical evaluation of free testosterone and cortisol immunoassays in saliva as a reliable alternative to serum in sports medicine. J Clin Lab Anal 2016;30(5):732735.

[8] Ushiki K, Tsunekawa K, Shoho Y, Martha L, Ishigaki H, Matsumoto R, et al. Assessment of exercise-induced stress by automated measurement of salivary cortisol concentrations within the circadian rhythm in Japanese female longdistance runners. Sports Medicine-Open 2020;6(1):38.

[9] Granger DA, Kivlighan KT, Fortunato C, Harmon AG, Hibel LC, Schwartz EB, et al. Integration of salivary biomarkers into developmental and behaviorally-oriented research: Problems and solutions for collecting specimens. Physiol Behav 2007;92(4):583-590.

[10] Shirtcliff EA, Granger DA, Schwartz E, Curran MJ. Use of salivary biomarkers in biobehavioral research: cotton-based sample collection methods can interfere with salivary immunoassay results. Psychoneuroendocrinology 2001;26(2):165-173.

[11] Borg GAV. Psychophysical bases of perceived exertion. Med Sci Sports Exerc 1982;14(5):377-381.

[12] Gagnon N, Frechette I, Mallet PL, Dube J, Houde G, Fink GD. Establishment of reference intervals for the salivary cortisol circadian cycle, by electrochemiluminescence (ECLIA), in healthy adults. ClinBiochem 2018;54:56-60.

[13] Matos-Gomes N, Katsurayama M, Makimoto FH, Santana LLO, Paredes-Garcia E, Becker MAD, et al. Psychological stress and its influence on salivary flow rate, total protein concentration and IgA, IgG and IgM titers. Neuroimmunomodulation 2010;17(6):396-404.

[14] Ligtenberg AJM, Liem EHS, Brand HS, Veerman ECI. The effect of exercise on salivary viscosity. Diagnostics 2016;6(4):40.

[15] Davies CTM, Few JD. Effects of exercise on adrenocortical function. J Appl Physiol 1973;35(6):887-891.

[16] Hill EE, Zack E, Battaglini C, Viru M, Viru A, Hackney AC. Exercise and circulating cortisol levels: The intensity threshold effect. J Endocrinol Invest 2008;31(7):587-591.

[17] Sato K, lemitsu M, Katayama K, Ishida K, Kanao Y, Saito M. Responses of sex steroid hormones to different intensities of exercise in endurance athletes. Exp Physiol 2016;101(1):168-175.

[18] Tremblay MS, Copeland JL, Van Helder W. Influence of exercise duration on post-exercise steroid hormone responses in trained males. Eur J Appl Physiol 2005;94(5-6):505-513.

[19] Anderson T, Lane AR, Hackney AC. Cortisol and testosterone dynamics following exhaustive endurance exercise. Eur J Appl Physiol 2016;116(8):1503-1509.

[20] Doan BK, Newton RU, Kraemer WJ, Kwon YH, Scheet TP. Salivary cortisol, testosterone, and T/C ratio responses during a 36-hole golf competition. Int J Sports Med 2007;28(6):470-479.

[21] Gatti R, De Palo EF. An update: salivary hormones and physical exercise. Scand J Med Sci 2011;21(2):157-169. 


\section{Figures}
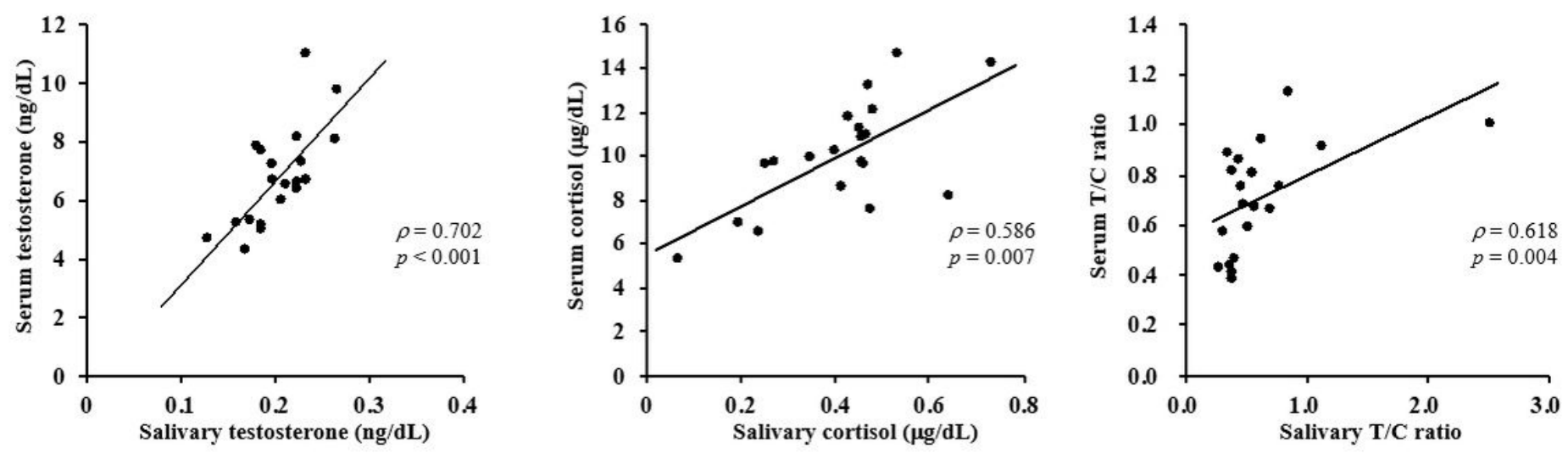

Figure 1

Spearman's correlation analyses between the salivary testosterone concentration and the serum testosterone concentration $(A)$, between the salivary cortisol concentration and the serum salivary concentration (B), and between the salivary $T / C$ ratio and the serum $T / C$ ratio $(C)$ measured by ECLIA in 20 male long-distance runners.

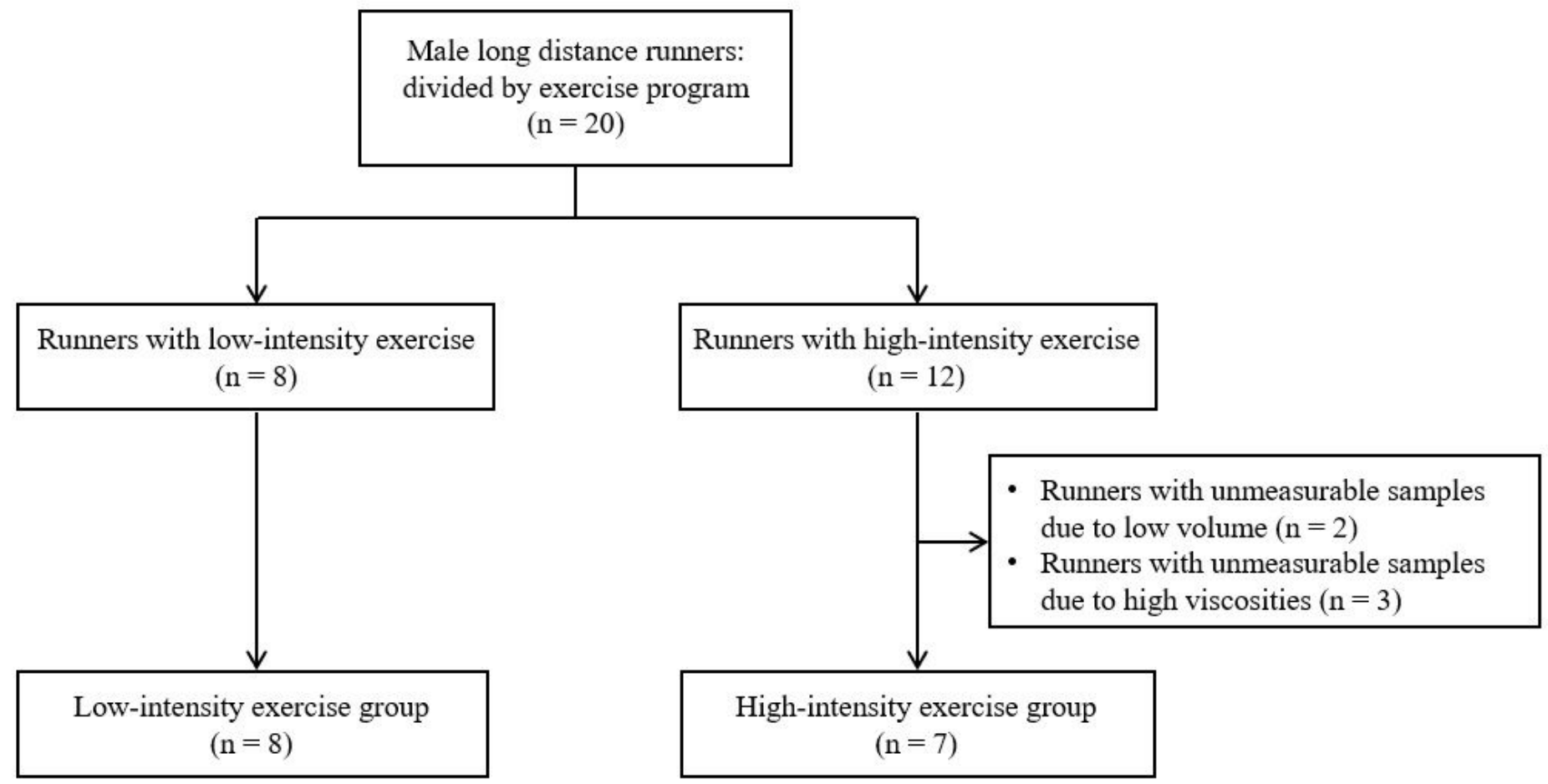

Figure 2

Group division of the male long-distance runners. 

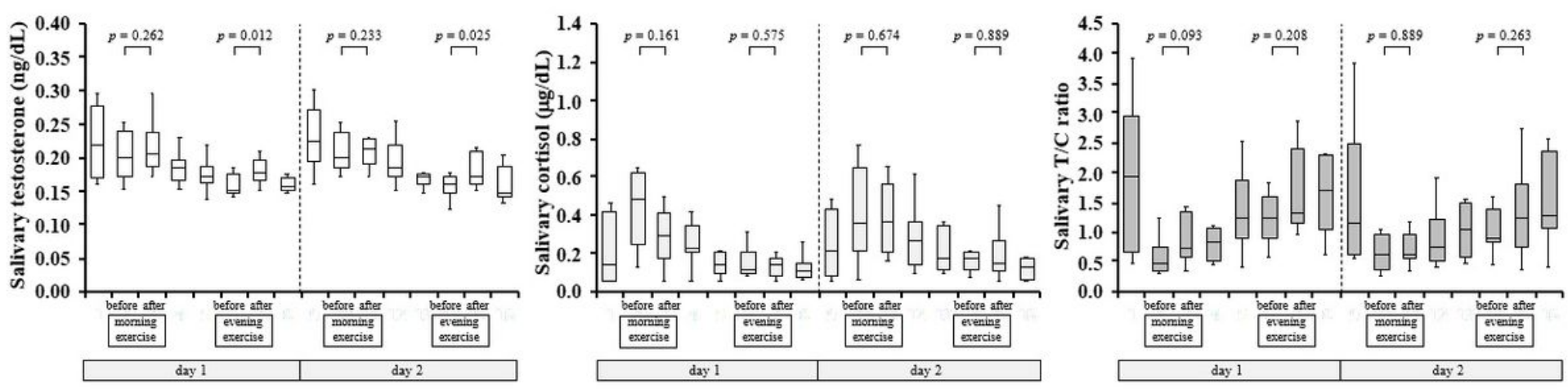

$\mathbf{B}$
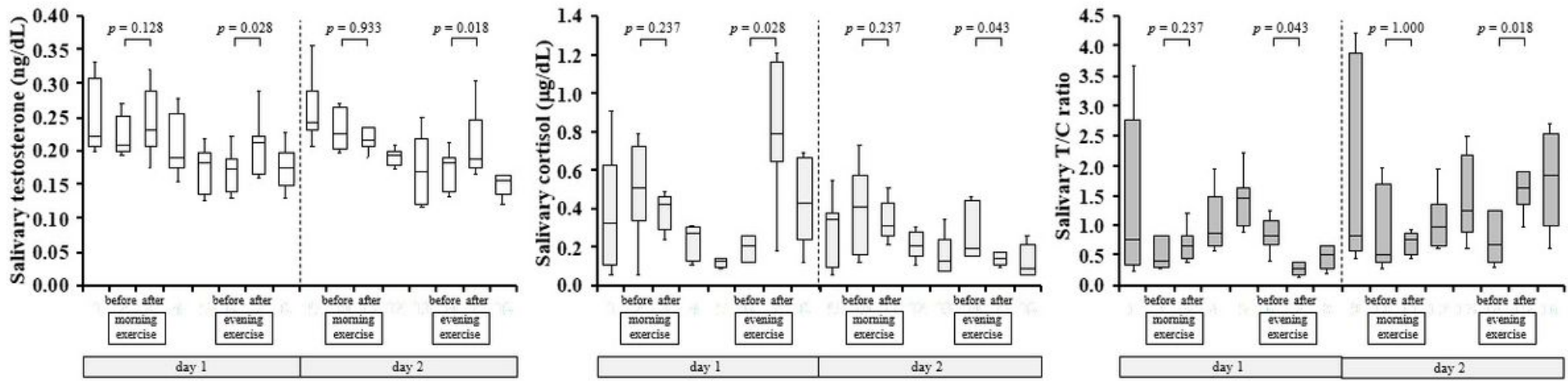

Figure 3

Changes in salivary testosterone concentration, salivary cortisol concentration and the salivary $\mathrm{T} / \mathrm{C}$ ratio in response to each exercise program during the circadian rhythm on two consecutive days in the low-intensity exercise group $(A, n=8)$ and high-intensity exercise group $(B, n=7)$.
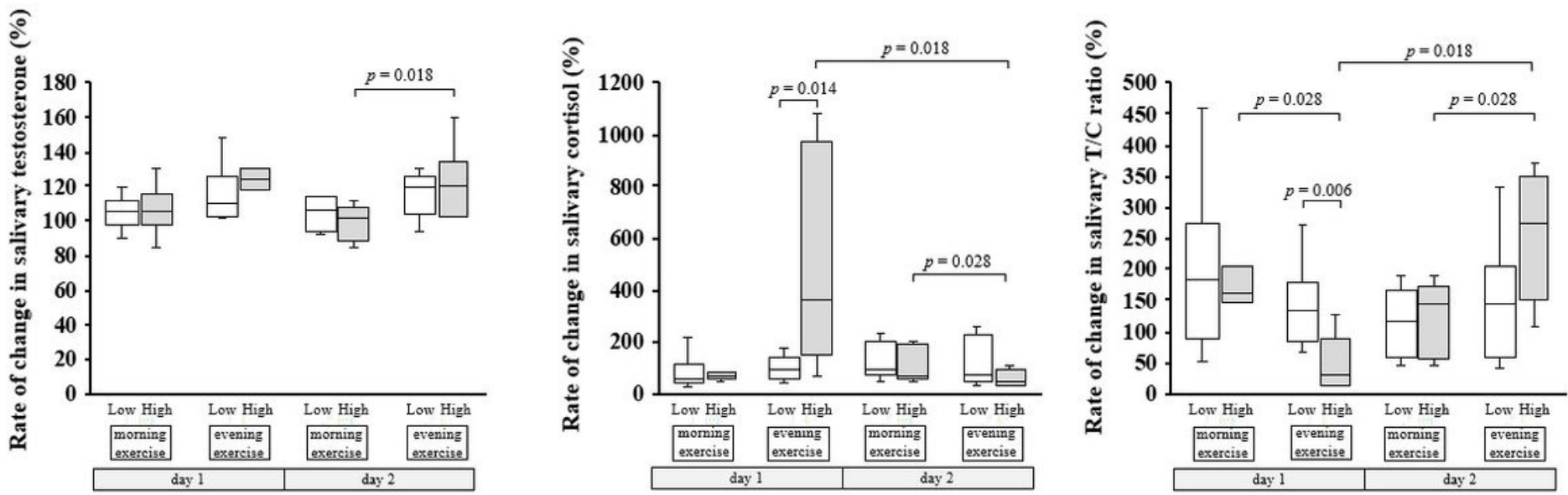

Figure 4

Comparison of the rate of change in the salivary testosterone concentration, the salivary cortisol concentration, and the $\mathrm{T} / \mathrm{C}$ ratio resulting from each exercise in the low-intensity and high-intensity exercise groups. The white box plots 
present the rates of change in each parameter in the low-intensity exercise group and the gray box plots present those in the high-intensity exercise group. The differences between the two groups were analyzed using the Mann-Whitney U test. The differences between the two time points of exercise for runners in the same group were analyzed using the Wilcoxon signed-rank test. 